\title{
REFLEXIÓN EN TORNO AL ENCUADRAMIENTO JURÍDICO DE LAS PERSONAS REPARTIDORAS DE PLATAFORMAS DIGITALES
}

\author{
Reflection around the legal framework of delivering people \\ of digital platforms \\ Raquel Poquet Catalá* \\ Universidad de Valencia, España
}

\begin{abstract}
RESUMEN
En este trabajo se realiza un análisis en torno a la consideración jurídica de la nueva prestación de servicios surgida en el contexto de la actual digitalización, concretamente, de las personas repartidoras de las plataformas digitales. Se parte del análisis de las notas de laboralidad, especialmente, de la dependencia o subordinación y de la ajenidad, frente a la caracterización de la persona trabajadora por cuenta propia. Asimismo, se realiza un estudio del Derecho comparado de nuestro entorno, concretamente, de Francia e Italia, y, a partir de todo ello, plantear propuestas regulatorias.
\end{abstract}

Palabras clave: plataforma digital, Persona repartidora, Economía de las plataformas.

\section{ABSTRACT}

In this paper, it is carried out an analysis on the legal consideration of the new provision of services that arose in the context of the current digitization, specifically, of the people who delivery through the digital platforms. This paper starts from the analysis of the work notes, especially dependency or subordination and alienation, compared to the characterization of the self-employed person. Likewise, it is realized a study of the comparative law of our country, specifically, of France and Italy, and, based on all this, propose regulatory proposals.

Keywords: digital platform, Delivery person, Platform economy.

\footnotetext{
* Correspondencia a: Raquel Poquet Catalá. Passeig de Les Germanies, 104, 5-9, 46702 Gandía (Valencia), España. raquel.poquet@uv.es — https: //orcid.org/0000-0001-9606-8832

Cómo citar: Poquet Catalá, Raquel. (2021). «Reflexión en torno al encuadramiento jurídico de las personas repartidoras de plataformas digitales"; Lan Harremanak, 45, 79-109. (https: //doi.org/10.1387/lan-harremanak.22798).

Recibido: 10 mayo, 2021; aceptado: 14 junio, 2021.

ISSN 1575-7048 - elSSN 2444-5819 / (c) 2020 UPV/EHU
} 


\section{Introducción}

La revolución digital, la automatización y la aparición de plataformas digitales ha planteado, entre otros, retos importantes al Derecho del Trabajo. Nuestra sociedad se halla inmersa en lo que se ha denominado la «digitalización de la economía» o la "cuarta revolución industrial» o «industria 4.0», y en este contexto surge la «economía de las plataformas».

Las plataformas digitales, íntimamente ligadas a la utilización de las nuevas tecnologías de la información y la comunicación, actúan en el mercado económico y laboral, ofreciendo servicios a consumidores pero a un precio más bajo, utilizando, para dichos servicios, a diversos actores que intervienen como intermediarios entre la plataforma digital y el consumidor final. Según la Comisión Europea la "gig economy» es definida como

modelos de negocio en los que se facilitan actividades mediante plataformas colaborativas que crean un mercado abierto para el uso temporal de mercancías o servicios ofrecidos a menudo por particulares. La economía colaborativa implica a tres categorías de agentes i) prestadores de servicios que comparten activos, recursos, tiempo y/o competencias - pueden ser particulares que ofrecen servicios de manera ocasional («pares») o prestadores de servicios que actúen a título profesional («prestadores de servicios profesionales»); ii) usuarios de dichos servicios; y iii) intermediarios que - a través de una plataforma en línea- conectan a los prestadores con los usuarios y facilitan las transacciones entre ellos («plataformas colaborativas»). Por lo general, las transacciones de la economía colaborativa no implican un cambio de propiedad y pueden realizarse con o sin ánimo de lucro ${ }^{1}$.

Esta nueva actividad económica, conocida coloquialmente como Uber Economy, consiste en que las empresas que gestionan las plataformas digitales no operan como meras intermediarias, facilitando simplemente el intercambio de bienes y servicios entre particulares, sino que, ellas mismas ofrecen determinados servicios al mercado, y para ello, se sirven de personas trabajadoras — ahora autónomas-.

$\mathrm{Y}$, en este contexto, las bases de las relaciones de trabajo sobre las que se ha sustentado tradicionalmente el Derecho Laboral han sufrido modificaciones considerables, alterando las estructuras y cimientos de la relación laboral, hasta el término de hablarse de «relaciones labores líquidas». Uno de los aspectos más importantes con los que se halla en estos momentos es en torno a la calificación jurídica que debe darse a los repartidores de estas plataformas digitales, los denominados «riders». Es decir, se trata de analizar si

${ }^{1}$ Comisión Europea, Una Agenda Europea para la economía colaborativa, Bruselas, 2 de junio de 2016 [COM (2016) 356 final], p. 5. Disponible en https: //eur-lex.europa.eu/legal-content/ES/ ALL/?uri=CELEX: 52016DC0356 (consultado el 26-5-2021) 
al excluir con carácter general estas plataformas digitales del ámbito de la relación laboral a quienes efectivamente prestan los servicios ofertados por las mismas, se ajustan a la legalidad vigente o, si por el contrario, incurren en una huida ilícita del Derecho del Trabajo, en virtud de la cual, trabajos que anteriormente eran prestados por trabajadores por cuenta ajena han pasado, mediante la irrupción de las nuevas tecnologías, a prestarse por cuenta propia o de forma independiente sin que dicha mutación se encuentre jurídicamente justificada (Moreno Gené, 2019: 65).

Como señala la doctrina, la innovación tecnológica participa de forma activa en la indefinición que se está produciendo en torno a los sujetos del contrato de trabajo, a través de nuevas formas de organización empresarial y nuevas formas de prestación de servicios por parte de las personas trabajadoras (Cavas Martínez, 2019: 65).

De ahí que para determinar si la relación que une a las plataformas con los prestadores de servicios tiene o no un carácter laboral, deberá acudirse al art. 1.1 Estatuto de los Trabajadores, aprobado por RD Legislativo 2/2015, de 23 de octubre, (en adelante, ET), que define a la persona trabajadora asalariada, analizando los elementos configuradores de la relación laboral, esto es, voluntariedad, personal, retribución, ajenidad y dependencia o subordinación. Concretamente, el art. 1.1 ET conceptúa las personas trabajadoras por cuenta ajena como aquellas que «voluntariamente presten sus servicios retribuidos por cuenta ajena y dentro del ámbito de organización y dirección de otra persona, física o jurídica, denominada empleador o empresario». De estas notas definidoras, las claves son la dependencia y la ajenidad. La dependencia supone la sujeción de la persona trabajadora a las facultades de dirección y control de la empresa, quedando sometida a las órdenes, instrucciones y control de esta ${ }^{2}$, mientras que la ajenidad implica que la persona trabajadora no asume los riesgos derivados del trabajo, pues es la empresa quien asume el riesgo y ventura de la actividad productiva, pudiéndose manifestar tanto en los frutos, como en los riesgos o propiedad de los medios de producción. En concreto, la ajenidad se construye sobre tres dimensiones, cuales son, la ajenidad en los frutos, de tal forma que la persona trabajadora cede ab initio los resultados de su trabajo a la empresa; la ajenidad en los riesgos, por la que la persona trabajadora lleva a cabo su trabajo a cambio de un salario, mientras que la empresa corre con los distintos riesgos, favorables o adversos, que se deriven de aquella actividad productiva; y la ajenidad en el mercado, pues entre la persona trabajadora que produce un bien o presta un servicio y el consumidor se interpone, jurídicamente hablando, un tercero, quien, co-

2 STS de 19 de febrero de 2014, rec. núm. 3205/2012, que señala que «la dependencia, [debe ser] entendida como esa integración en el ámbito de organización y dirección del empresario (es decir, la ajenidad respecto a la organización de la propia prestación laboral), que es la fórmula que emplea el artículo 1 del ET, cristalización de una larga elaboración jurisprudencial en la que se concluyó que no se opone a que concurra esta nota de la dependencia la autonomía profesional imprescindible en determinadas actividades». 
brando un precio por el bien o servicio, paga un salario a la persona trabajadora (Sáenz de Buruaga Azcargorta, 2019: 403).

Por el contrario, la persona trabajadora por cuenta propia o autónoma es definida en el art. 1.1 Ley del Estatuto del Trabajador Autónomo, Ley 20/2007, de 11 de julio (en adelante, LETA) como aquella que realiza «de forma habitual, personal, directa, por cuenta propia y fuera del ámbito de dirección y organización de otra persona, una actividad económica o profesional a título lucrativo, den o no ocupación a trabajadores por cuenta ajena». De esta definición se extraen como características esenciales de la misma el que sea un trabajo personal y directo, habitual, por cuenta propia, con independencia organizativa y con ánimo de lucro.

La diferencia entre la persona trabajadora por cuenta ajena y por cuenta propia se halla básicamente en las dos notas esenciales citadas anteriormente, esto es, en la dependencia y la ajenidad pues, tal y como tiene seńalado nuestro alto tribunal, «la naturaleza de los contratos no se determina por la denominación que le otorgan las partes, sino por la realidad de las funciones que en su virtud tengan lugar ${ }^{3}$. Y es aquí donde se halla el escollo de la cuestión, pues las nuevas tecnologías de la información y la comunicación han flexibilizado en gran manera estas notas de subordinación y dependencia permitiendo múltiples formas de organización del trabajo que, a pesar de ser por cuenta ajena, gozan de flexibilidad y libertad en la organización del trabajo. De ahí, que nuestro alto tribunal $^{4}$ haya declarado que el trabajo subordinado no es incompatible con un espacio de autonomía o libertad en el desarrollo de la prestación de servicios.

El art. 11.1 LETA define a las personas trabajadoras económicamente dependientes como aquellas

que realizan una actividad económica o profesional a título lucrativo y de forma habitual, personal, directa y predominante para una persona física o jurídica, denominada cliente, del que dependen económicamente por percibir de él, al menos, el 75 por ciento de sus ingresos por rendimientos de trabajo y de actividades económicas o profesionales.

Por tanto, y a diferencia de la persona asalariada, se recogen aquí tres elementos constitutivos, cuales son, el trabajo ha de ser personal, desarrollado en régimen de dependencia económica y con ausencia de subordinación jurídica. Como se observa, en este precepto, aparecen elementos propios del trabajo por cuenta propia, con otros elementos que reiteran características que se desprenden de forma directa de la relación laboral por cuenta ajena (Galiana Moreno y

\footnotetext{
3 STS de 21 de enero de 2000, rec. núm. 582/1999.

4 SSTS de 19 de febrero de 2014, rec. núm. 3205/2012; de 6 de octubre de 2010, rec. núm. 2010/2009.
} 
Selma Penalva, 2009: 294). No cabe duda de la autonomía funcional y de organización de los TRADE, ya que prestan su actividad en base a criterios propios, aunque limitados a la cuota de mercado. No se trata de una persona trabajadora autónoma que dispone libremente de sus servicios para los consumidores que conformen el mercado de trabajo, sino que queda restringido su poder de decisión a un solo cliente del que obtiene el $75 \%$ de sus ingresos. De cualquier forma, la característica fundamental de esta figura es su dependencia económica, que no debe confundirse con la dependencia jurídica (Montoya Melgar, 2005: 39), pues la dependencia económica queda institucionalizada a través de un contrato de prestación de servicios que debe registrarse en la oficina pública correspondiente. La dependencia entre el TRADE y su cliente no es sólo económica, sino que este último ejerce una función de coordinación que resulta de contornos imprecisos pero en cuyo fondo no es difícil descubrir algo muy parecido a la dependencia jurídica, aunque más debilitada.

De ahí, la necesidad de una regulación que aclare la situación de estas personas repartidoras. El RDL 9/2021, de 11 de mayo, para garantizar los derechos laborales de las personas dedicadas al reparto en el ámbito de plataformas digitales, incluye dos disposiciones. Una de ellas es el establecimiento de una presunción de laboralidad por la que las personas que presten servicios retribuidos consistentes en el reparto o distribución de productos, por parte de empresas que ejercen las facultades empresariales de organización, dirección y control de forma directa, indirecta o implícita, mediante la gestión algorítmica del servicio o de las condiciones de trabajo, a través de una plataforma digital, se consideran relaciones laborales sujetas al ET. Por tanto, se aboga por la laboralidad de esta relación prohibiendo que los riders sean falsas personas trabajadoras autónomas. Tras varios meses de negociaciones, el acuerdo alcanzado pasa por definir la relación entre los riders y las plataformas digitales como laboral y no como mercantil, de tal forma que las plataformas deberán dar de alta en el régimen general de la Seguridad Social a las personas repartidoras sin que puedan ser personas trabajadoras autónomas.

En la segunda disposición se modifica el art. 64 ET para incluir la obligación de las plataformas de informar a la representación legal de las personas trabajadoras de las reglas que encierran los algoritmos y los sistemas de inteligencia artificial que pueden incidir en las condiciones laborales por las que se rigen las plataformas, incluyendo el acceso y mantenimiento del empleo y la elaboración de perfiles. Como es sabido, el algoritmo que utilizan estas plataformas, según la posición de la persona repartidora, el pedido que se realiza, y la distancia a recorrer, escoge al rider que más minimice los costes del reparto y aumente los beneficios. Además, con él también reparte las horas que las personas repartidoras pueden trabajar, siendo las noches del fin de semana las de mayor disponibilidad, y premia con más pedidos a aquellas que más puntuación y más repartos hagan. Por contra, también penaliza la puntuación a aquellas personas repartidoras que rechazan realizar un pedido. 


\section{Caracterización fáctica de las plataformas y los riders}

Debe partirse de la indicación de que existen diversos tipos de plataformas digitales, que pueden clasificarse de acuerdo con criterios diferentes, esto es, en función de la titularidad, naturaleza económica, tipo de transacciones, lugar de prestación de los servicios... No obstante, a estos efectos, interesan aquellas plataformas digitales que no actúan como meras intermediarias, sino que realizan una gestión de los servicios, utilizando para ello personal con el que cuentan hallándose en este último aspecto, la cuestión sobre la naturaleza jurídica del vínculo que le une a su personal.

Si se analizan los datos fácticos del funcionamiento de esta nueva forma de prestación de servicios, pueden destacarse los siguientes.

En primer lugar, estamos ante empresas que mediante la gestión de una plataforma informática prestan servicios de recadería y reparto vía web, o App. Para ello, se sirven de una aplicación que pone en contacto a consumidores o usuarios de la plataforma que están interesados en un determinado producto, siéndosele entregado mediante unas personas repartidoras utilizando su bicicleta, motocicleta o patinete eléctrico. Los usuarios de la plataforma pueden realizar un pedido de mensajería, a través del cual la empresa recoge el producto en el lugar indicado por el usuario y lo entrega en el lugar indicado por el mismo, o bien un pedido de recadería, a través del cual se encarga a la empresa que compre un determinado producto y que le sea entregado en el lugar indicado por el usuario. Para realizar dichas entregas, la plataforma se sirve de los mensajeros-repartidores o «riders» o también denominados «glovers».

En segundo lugar, las personas repartidoras reservan, durante la semana anterior, mediante la App la franja horaria en la que desea trabajar para la siguiente semana. Si tiene abierta la aplicación en la franja horaria y en la zona geográfica elegida, le entran los pedidos requeridos para dicha franja y zona. La persona repartidora puede aceptar o no el pedido. Si lo acepta de forma automática, la plataforma le asigna un reparto automático de recados que la persona trabajadora puede rechazar de forma manual. Si lo acepta de forma manual, la plataforma no asigna el pedido a la persona repartidora, sino que es éste quien tiene que seleccionar qué reparto desea hacer de entre los disponibles. Por tanto, la persona repartidora decide el momento de inicio y finalización de su jornada, así como la actividad, seleccionando los pedidos que quiere y los que no, sin que exista obligación de realizar un determinado número de pedidos, ni estar en activo un mínimo de horas al día o a la semana.

En tercer lugar, el sistema de asignación de pedidos automático se realiza por el algoritmo, siguiendo una función de coste-beneficio que busca la mejor combinación posible pedido-persona repartidora que minimice la suma de costes. 
En cuarto lugar, existe un sistema de puntuación de las personas repartidoras o "glovers» calificándolas en diferentes categorías, de tal forma que, si una persona repartidora lleva más de tres meses sin aceptar ningún servicio, la empresa puede darle de baja de categoría. La puntuación depende de la valoración del cliente final, de la eficiencia demostrada en la realización de los pedidos más recientes y de la realización de los servicios en las horas de mayor demanda. Además, cada vez que una persona repartidora no está operativa en la franja horaria previamente reservada por ella existe una penalización en los puntos ${ }^{5}$.

En quinto lugar, las herramientas de trabajo (vehículo de reparto y teléfono móvil) pertenecen a la persona repartidora, quien «asume el riesgo y ventura de cada pedido y responde del mismo frente al cliente, que también es quien puntúa su trabajo» ${ }^{6}$.

En sexto lugar, la empresa establece unas instrucciones y protocolo a seguir en cuanto al comportamiento de la persona repartidora, pues ésta debe quitarse el casco y la mochila cuando entre en el restaurante o acuda a un domicilio, cómo debe ir vestido, y llevar visible la marca de la empresa. El nivel de detalle de las instrucciones llega hasta el siguiente extremo:

¿Qué hacer en caso de derrame de líquidos o comida sólida? Ponerse en contacto con Chat de Soporte y avisar del incidente, para que atención al Cliente se ponga en contacto inmediato con el cliente. Secar con papel absorbente el interior del equipamiento. Limpiar con jabón todo el interior del equipamiento, y aclarar el resultado. Aplicar el desinfectante en el interior del equipamiento, y aclarar con toallas de papel para secarlo definitivamente ${ }^{7}$.

En séptimo lugar, el sistema de retribución de la persona trabajadora consiste en el pago de una cantidad por pedido, a la que se añade otra cantidad por kilómetros y tiempo de espera, quedándose una parte la plataforma en concepto de comisión por la intermediación realizada. La empresa le abona la retribución mediante transferencia bancaria con el concepto, muchas veces, de «nómina».

En octavo lugar, la persona repartidora está permanentemente localizada a través de un geolocalizador GPS, con el cual se controla el kilometraje invertido en los desplazamientos, aunque la persona repartidora tiene libertad para elegir sus rutas.

En noveno lugar, la persona repartidora utiliza una tarjeta de débito entregada por Glovo para adquirir los productos que debe entregar al cliente. En las facturas constan los gastos realizados por la persona repartidora con dicha tarjeta y se compensan como un abono de gastos o suplidos.

\footnotetext{
5 SJS núm. 17 Madrid, de 11 de enero de 2019, rec. núm. 418/2018.

6 SJS núm. 39 Madrid, de 3 de septiembre de 2018, rec. núm. 1353/2017.

7 Acta de la Inspección de Trabajo y Seguridad Social de Valencia de 18 de diciembre de 2017.
} 
En el caso concreto de Glovo, debe indicarse que Glovo es el nombre comercial con el que se conoce a la entidad mercantil Glovoapp23, S.L., constituida en Barcelona en el año 2014. Su objeto social es la «explotación de aplicaciones informáticas de servicios de recadero con facultad de adquisición de bienes por cuenta ajena actuando como comisionista», así como, la "realización de la actividad de intermediario en la contratación de transporte de mercancías por carretera en concepto de agencia de transporte, transitorio, almacenista distribuidor u operador logístico» ${ }^{8}$. Tal actividad, así formalmente descrita, la ha llevado a adherirse al código CNAE número 6209, correspondiente a «otros servicios relacionados con las tecnologías de la información y la informática» y al código SIC número 7379, que identifica «servicios relacionados con la computación SC».

En su propia web se describe su objeto social presentándose como una empresa de tecnología y una empresa informática. De hecho, en su web empresarial, se autodefine como una "compañía tecnológica» y subraya que su «actividad principal es el desarrollo y gestión de una plataforma tecnológica»? ${ }^{9}$ Para acceder a dicha plataforma de carácter virtual, se puede utilizar una aplicación móvil —app móvil—o una aplicación web —app web—, denominada GlovoApp.

\section{Posición de la doctrina judicial}

\subsection{Sector que aboga por su laboralidad}

La posición de la doctrina judicial mayoritaria es la de considerar que esta relación entre plataforma digital y persona repartidora es la de una relación laboral sometida a las reglas del Estatuto de los Trabajadores, en base a que se cumplen los requisitos de laboralidad, especialmente, la dependencia y la ajenidad.

En este sentido, uno de los primeros órganos judiciales en pronunciarse sobre estas personas repartidoras fue el Juzgado de lo Social de Valencia ${ }^{10}$ que las

8 SJS núm. 33 Madrid, de 11 de febrero de 2019, rec. núm. 1214/2018 y STSJ Madrid, de 19 de septiembre de 2019, rec. núm. 195/2019.

9 Cláusula 1. Disponible en https: //glovoapp.com/en/legal/terms

10 SJS núm. 6 Valencia, de 1 de junio de 2018, proc. núm. 633/2017. En el mismo sentido se sitúan las SSJS núm. 11 Barcelona, de 29 de mayo de 2018, rec. núm. 652/2016; núm. 1 Gijón, de 20 de febrero de 2019, rec. núm. 724/2018; núm. 1 Madrid, de 3 de abril de 2019, rec núm. 994/2018; núm. 1 Madrid, de 4 de abril de 2019, rec. núm. 496/2018; núm. 24 Barcelona, de 21 de mayo de 2019, rec. núm. 143/2018; núm. 5 Valencia, de 10 de junio de 2019, rec. núm. 371/2018; núm. 31 Barcelona, de 11 de junio de 2019, rec. núm. 662/2017; núm. 19 Madrid, de 22 de julio de 2019, rec. núm. 510/2018 y núm. 2 Zaragoza, de 27 de abril de 2020, rec. núm. 521/2018. También, SSTSJ Madrid, de 27 de noviembre de 2019, rec. núm. 588/2019; Madrid, de 18 de diciembre de 2019, rec. núm. 714/2019; Madrid, de 17 de enero de 2020, rec. núm. 1323/2019; Madrid, de 3 de febrero de 2020, rec. núm. 749/2019; Castilla y León, de 17 de febrero de 2020, rec. núm. 2253/2019; Cataluńa, de 21 de febrero de 2020, rec. núm. 5613/2019 y Cataluña, de 7 de mayo de 2020, rec. núm. 5647/2019. 
considera laborales. En este caso, estima que el dato fático de que la persona repartidora tenga licencia fiscal como autónoma, que aporte la bicicleta y el móvil para prestar su trabajo, que tenga la posibilidad de buscar una persona sustituta para realizar los repartos o que tenga libertad para fijar las franjas horarias en que quiere prestar sus servicios es irrelevante, pues considera que se dan todos los presupuestos que definen la existencia de una relación laboral, ya que

era la empresa la que decidía la zona en la que el trabajador debía desempeñar sus funciones. En cuanto al horario, siendo cierto que el trabajador ofertaba a la empresa las franjas horarias en las que quería trabajar, también lo es que esas franjas tenían que estar dentro del horario previamente establecido por la demandada, y que era ésta quien finalmente decidía en qué horario iba a desempeñar sus funciones el trabajador cada semana, siendo que en ocasiones éste quedaba reducido a una parte del solicitado por el trabajador. Respecto al servicio de reparto, la empresa daba instrucciones concretas a los repartidores sobre la forma en que éste se tenía que llevar a cabo, fijando tiempos y normas de comportamiento que éstos debían cumplir. Consta, así mismo, que al inicio del turno asignado los trabajadores debían acudir al lugar fijado por la empresa, centroide, para que ésta les asignara servicios a través de la plataforma, debiendo retornar a ésta cada vez que finalizaban un servicio. Además, la empresa tenía en todo momento geolocalizado al trabajador, a quien podía pedir explicaciones en cualquier momento sobre el servicio, llevando un control de tiempos de cada reparto, siendo la empresa la que decidía en cada momento sobre los repartos a realizar y la efectiva asignación de los $\operatorname{mismos}^{11}$.

También una sentencia posterior del Juzgado de lo Social de Madrid ${ }^{12}$ entiende que la relación es laboral. Si bien entiende que han quedado acreditados una serie de indicios caracterizadores del trabajo no subordinado (es libre para decidir los días que trabaja y los que no, la franja horaria, rechazar y cancelar pedidos, elegir períodos de descanso y vacaciones, organizar la prestación del servicio), prevalecen otros que permiten afirmar lo contrario. Del mismo modo, se pronuncia el Juzgado de lo Social núm. 19 de Madrid ${ }^{13}$, que realiza un análisis de los elementos esenciales en una relación laboral — dependencia y por cuenta ajena-, apoyándose en la doctrina jurisprudencial de la STS de 26 de febrero de 1986, para ir descartando su declaración como trabajador por cuenta propia.

En esta misma línea, la Audiencia Nacional ${ }^{14}$, aunque no siendo el fondo del asunto, pues el debate se centra en si es posible que la empresa obligue a sus personas repartidoras a aportar sus propios teléfonos en los que se descargan una App que permite a la misma geolocalizar a los motoristas durante su jornada la-

11 SJS núm. 6 Valencia, de 1 de junio de 2018, rec. núm. 633/2017.

12 SJS núm. 33 Madrid, de 11 de febrero de 2019, rec. núm. 1214/2018. En el mismo sentido, SSJS núm. 1 Madrid, de 3 de abril de 2019, rec. núm. 994/2018 y núm. 1 Madrid, de 4 de abril de 2019, rec. núm. 946/2018.

13 SJS núm. 19 Madrid, de 22 de julio de 2019, rec. núm. 510/2018.

14 SAN de 6 de febrero de 2019, rec. núm. 338/2018. 
boral, considera que la geolocalización es un sistema de control del comportamiento de los riders, y por tanto, en cierta forma, está calificando a las personas repartidoras como trabajadoras por cuenta ajena.

Debe destacarse la primera sentencia de un Tribunal Superior de Justicia sobre esta problemática ${ }^{15}$. En esta sentencia se vuelven a analizar los dos elementos clave para la declaración de una relación como laboral. En este sentido, en cuanto a la ajenidad en los elementos de producción, considera que

es impensable que el actor pudiera desempeñar su trabajo transportando comidas entre los restaurantes y los eventuales clientes, en calidad de trabajador autónomo, al margen de la plataforma y con sus solos medios (con su vehículo y con su móvil), ya que el éxito de este tipo de plataformas, se debe precisamente al soporte técnico proporcionado por las TIC que emplean para su desarrollo y a la explotación de una marca, en este caso Glovo, que se publicita en redes sociales a través de los buscadores tipo Google, sitio al que acuden los clientes cuando necesitan la compra y entrega de comida y los productos que la demandada suministra.

Por lo que se refiere a la dependencia, estima que no se está ante una coordinación de actividades empresariales como si se tratara de dos empresas, sino ante una persona trabajadora que presta sus servicios bajo las órdenes de la empresa pues «lo que la empresa propietaria de la plataforma hace es imponer una serie de normas que el trabajador que quiera asociarse debe cumplir». Asimismo, recurre a la Directiva 2019/1152, de 20 de junio de 2019, relativa a unas condiciones laborales transparentes y previsibles en la Unión Europea, que pretende avanzar una respuesta normativa comunitaria en relación con el «trabajo atípico", en el que podemos incluir el desarrollado para las plataformas digitales de servicios, señalando en su parte introductoria que

en su jurisprudencia, el Tribunal de Justicia de la Unión Europea (desde el asunto C-66/85 LawrieBlum al más reciente asunto C-216/15 Ruhrlandklinik) ha establecido criterios para determinar el estatus de un trabajador. La interpretación que el Tribunal de Justicia hace de esos criterios debe tenerse en cuenta en la aplicación de la presente Directiva. Siempre que cumplan esos criterios, los trabajadores domésticos, los trabajadores a demanda, los trabajadores intermitentes, los trabajadores retribuidos mediante vales, los trabajadores de las plataformas en línea, los trabajadores en prácticas y los aprendices pueden estar incluidos en el ámbito de aplicación de esta Directiva.

Los posteriores pronunciamientos de suplicación ${ }^{16}$ siguen esta misma línea. Se coincide en que las notas de ajenidad y dependencia están presentes. Y, aun-

15 STSJ Asturias, de 25 de julio de 2019, rec. núm. 1143/2019.

16 SSTSJ Madrid, de 27 de noviembre de 2019, rec. núm. 588/2019; Madrid, de 18 de diciembre de 2019, rec. núm. 714/2019; Madrid, de 17 de enero de 2020, rec. núm. 1323/2019; Madrid, de 3 de febrero de 2020, rec. núm. 749/2019; Castilla y León, de 17 de febrero de 2020, rec. 
que reconoce la inexistencia de la obligación de la persona repartidora de estar disponible y que puede escoger los servicios a realizar, a su criterio, se trata de una facultad muy condicionada, pues las personas repartidoras deben elegir los días y franjas horarias en los que van a prestar sus servicios y lo deben hacer constar en la aplicación, existiendo unas franjas más solicitadas, cuya elección depende del sistema de puntuación. Y ahí el control de horarios a través de las retribuciones y las valoraciones.

Es decir, se considera que el hecho de que la persona repartidora no tenga obligación de estar disponible y que pueda elegir los servicios a realizar y los itinerarios, a lo que se añade que la retribución es por encargo, que no hay horario, ni jornada, ni régimen de permisos, y ni vacaciones, son elementos no determinantes del contrato de trabajo, sino meras consecuencias de la regulación jurídica propia de esta actividad de prestación de servicios. La ausencia de estos elementos no excluye la laboralidad de esta nueva modalidad de organización laboral. Por el contrario, lo relevante es el dato de que las personas repartidoras están sometidas al poder de dirección y control de la empresa pues, aunque tenga libertad para aceptar o rechazar la realización de cada servicio, si lo acepta, lo debe ejecutar cumpliendo con las instrucciones dadas por la empresa, lo que, constituye una muestra clara de su sumisión a la empresa. En otros términos, la persona repartidora no trabaja según sus propios criterios, sino que queda sometida a los de la empresa, siendo ésta la que establece un sistema de trabajo (dependencia), con una formación previa que debe llevar a cabo y un control por evaluaciones (ajenidad en el uso de la fuerza de trabajo).

Además, debe tenerse presente que el valor principal de dicho negocio no lo es el medio de transporte de la persona repartidora, como a veces se ha alegado, sino la propia plataforma digital y la aplicación de acceso de los usuarios, permitiéndose así que puedan actuar con eficacia en el mercado de servicios (ajenidad en los medios de producción). Asimismo, no cabe duda de que la persona repartidora no asume riesgo alguno, sino que percibe una retribución fija por servicio realizado con independencia del resultado del negocio y, siendo así, ajeno a que la empresa gane o pierda dinero (ajenidad en los riesgos). A la postre, el usuario únicamente actúa en el mercado de bienes y servicios, y el rider en el mercado de trabajo, de forma que no existe ninguna relación contractual o jurídica entre el rider y el usuario o consumidor final (ajenidad en el mercado) (Moreno Gené; 2020: 566).

Por último, el recién pronunciamiento de nuestro alto tribunal ${ }^{17}$, dictado en unificación de doctrina, y anulando, en parte la STSJ Madrid, de 19 de sep-

núm. 2253/2019; Cataluña, de 21 de febrero de 2020, rec. núm. 5613/2019 y Cataluña, de 7 de mayo de 2020, rec. núm. 5647/2019.

17 STS de 25 de septiembre de 2020, rec. núm. 4746/2019. 
tiembre de 2019, rec. núm. 195/2019, confirmando la SJS núm. 39 Madrid, de 3 de septiembre de 2018, estima en parte el recurso de casación, abogando, pues, por su laboralidad.

El TS parte de la base de que

la realidad fáctica debe prevalecer sobre el nomen iuris porque los contratos tienen la naturaleza que se deriva de su real contenido obligacional, independientemente de la calificación jurídica que les den las partes; de modo que a la hora de calificar la naturaleza laboral o no de una relación debe prevalecer sobre la atribuida por las partes, la que se derive de la concurrencia de los requisitos que determinan la laboralidad y de las prestaciones realmente llevada a cabo.

Por tanto, la línea divisoria entre el contrato de trabajo y otros vínculos de naturaleza análoga, como el contrato de arrendamiento de servicios, regulados por la legislación civil o mercantil, no aparece nítida ni en la doctrina, ni en la legislación, pues en el contrato de arrendamientos de servicios el esquema de la relación contractual es un genérico intercambio de obligaciones y prestaciones de trabajo con la contrapartida de un precio o remuneración de los servicios, pues el contrato de trabajo es una especie del género anterior.

Nuestro alto tribunal considera que, aunque la plataforma y la persona trabajadora suscribieron un contrato de TRADE no concurren las condiciones del art. 11.2 L 20/2007, concretamente, no tener a su cargo personas trabajadoras por cuenta ajena ni contratar o subcontratar parte o toda la actividad con terceros; no ejecutar su actividad de manera indiferenciada con las personas trabajadoras que presten servicios bajo cualquier modalidad de contratación laboral por cuenta del cliente; disponer de infraestructura productiva y material propios, necesarios para el ejercicio de la actividad e independientes de los de su cliente, cuando en dicha actividad sean relevantes económicamente; desarrollar su actividad con criterios organizativos propios, sin perjuicio de las indicaciones técnicas que pudiese recibir de su cliente; percibir una contraprestación económica en función del resultado de su actividad, de acuerdo con lo pactado con el cliente y asumiendo riesgo y ventura de aquella. Concretamente, considera que la tercera y cuarta condición no se cumplen puesto que no dispone de infraestructura productiva ni de material propio para poder operar por cuenta propia, ya que sólo dispone de una moto y un teléfono móvil. Además, considera que estos elementos son accesorios o complementarios, siendo la infraestructura básica para poder ejercer esta actividad la plataforma digital de Glovo que pone en contacto los comercios con los clientes.

Analizando las notas de la laboralidad, especialmente, la subordinación o dependencia y la ajenidad, en relación con la primera de ellas, el órgano judicial recuerda que la dependencia «no implica una subordinación absoluta, sino sólo 
la inserción en el círculo rector, organizativo y disciplinario de la empresa» ${ }^{18}$, pero que dicha nota ha sido flexibilizada con las nuevas formas de organización del trabajo, y la nueva realidad social, debiendo aplicarse el principio del art. 3.1 CC. De ahí, que señale que es evidente que existe una dificultad para valorar la presencia de los elementos definitorios de la relación laboral en los supuestos dudosos. Por ello, recurre a la doctrina judicial comunitaria ${ }^{19}$ que señala que el concepto de persona trabajadora es la de aquella «que realiza, durante un período de tiempo determinado, en favor de otra y bajo la dirección de ésta, ciertas prestaciones por las cuales percibe una remuneración».

Estima que el hecho de que la persona trabajadora pueda rechazar clientes o servicios, y elegir la franja horaria para prestar servicios son indicios no propios de una relación laboral. Aunque, debe tenerse en cuenta que esta teórica libertad para rechazar clientes o servicios o elegir la franja horaria no es tal en el sentido de que el rider puede ser penalizado, ya que las personas repartidoras con mayor puntuación tienen preferencia de acceso a los servicios. Por ello, este sistema de puntuación condiciona, en cierta forma, la libertad de elección de horarios.

A la postre, el máximo órgano judicial señala otros indicios de laboralidad. En primer lugar, el sistema de puntuación existente basado, entre otros aspectos, en la valoración del cliente final. En segundo lugar, la geolocalización de la persona trabajadora a través de GPS mientras realiza su actividad, registrando los $\mathrm{km}$ que recorre. En tercer lugar, Glovo no se limita a encomendar a la persona repartidora la realización de un servicio, sino que también indica cómo prestarse, y controlando que se cumplan las indicaciones a través de la aplicación. En cuarto lugar, la plataforma proporciona a la persona trabajadora una tarjeta de crédito para que pueda comprar productos para el usuario. En quinto lugar, Glovo abona una compensación económica por el tiempo de espera, esto es, el tiempo que el rider está en el lugar de recogida esperando su pedido. Por último, existe un grupo de supuestos que justifican la resolución del contrato por la empresa, consistentes en incumplimientos del rider.

En cuanto a la nota de ajenidad, el alto tribunal considera que Glovo es quien toma las decisiones comerciales, fija el precio de los servicios, la forma de pago y la remuneración de las personas repartidoras, ya que estas, como se ha indicado, no reciben sus honorarios directamente de los clientes finales, sino que el precio lo recibe Glovo, y Glovo abona la retribución correspondiente a las personas repartidoras. No obstante, en cuanto a la ajenidad en los riesgos, el hecho de que el rider asuma frente al cliente final los daños o pérdidas que puedan sufrir los productos durante el transporte, es contrario a la laboralidad de la relación, porque, normalmente, las personas trabajadoras no responden frente al cliente de estos daños o

18 STS de 11 de mayo de 1979.

19 STJUE de 13 de enero de 2004, Cao Debra Allonby contra Accrington \& Rossendale College. 
pérdidas. Además, el rider asume el riesgo de la utilización de su motocicleta y móvil propios, cuyos costes corren a su cargo. Pone de relieve, además, la escasísima cuantía en inversión que la persona trabajadora debe realizar para desarrollar la actividad (teléfono y bicicleta, motocicleta o patinete) frente a la inversión que realiza la empresa (plataforma, programa informático, vehículos de transporte pesados...)

En relación con la ajenidad en los frutos, el Tribunal Supremo estima que el hecho de que Glovo se apropie de manera directa del resultado de la prestación de trabajo, redunda en beneficio de la empresa. Además, la persona repartidora no tiene ninguna intervención en los acuerdos establecidos entre Glovo y los comercios, y es la empresa quien fija con los distintos establecimientos los precios. Por lo que se refiere a la ajenidad en los medios, el órgano judicial declara que, obviamente, los medios de producción esencial no son el teléfono móvil y la motocicleta, sino la plataforma digital de Glovo.

Por ello, estima que Glovo no es una mera intermediaria, sino que es una empresa que presta servicios de recadería fijando el precio y las condiciones, siendo titular de los activos esenciales para realizar la actividad, sirviéndose de ello de personas repartidoras que no disponen de una organización empresarial propia y autónoma, las cuales prestan sus servicios dentro del ámbito de organización de la plataforma.

En definitiva, señala la necesidad de adaptar los requisitos de dependencia y ajenidad al contexto actual:

Desde la creación del derecho del trabajo hasta el momento actual hemos asistido a una evolución del requisito de dependencia-subordinación. La sentencia del TS de 11 de mayo de 1979 ya matizó dicha exigencia, explicando que «la dependencia no implica una subordinación absoluta, sino sólo la inserción en el círculo rector, organizativo y disciplinario de la empresa». En la sociedad postindustrial la nota de dependencia se ha flexibilizado. Las innovaciones tecnológicas han propiciado la instauración de sistemas de control digitalizados de la prestación de servicios. La existencia de una nueva realidad productiva obliga a adaptar las notas de dependencia y ajenidad a la realidad social del tiempo en que deben aplicarse las normas.

\subsection{Sector que aboga por su no laboralidad}

Pueden encontrarse diversos pronunciamientos —aunque son los menosque consideran que se trata de una auténtica relación mercantil, esto es, de una persona trabajadora por cuenta propia.

De esta forma, el Juzgado de lo Social de Madrid ${ }^{20}$ ha declarado la no laboralidad de estos repartidores por considerarlos TRADE. Señala que el demandante

20 SJS núm. 39 Madrid, de 3 de septiembre de 2018, rec. núm. 1353/2017. En el mismo sentido, SSJS núm. 24 Barcelona, de 29 de mayo de 2019, rec. núm. 144/2018 y núm. 1 Salamanca, de 14 de junio de 2019, rec. núm. 133/2019. 
no tenía jornada ni horario. Él decidía la franja horaria en la que deseaba trabajar, elegía los pedidos que le interesaban y rechazaba los que no quería, decidía con libertad la ruta a seguir hasta cada destino, no tenía obligación de comenzar o finalizar su jornada en una determinada hora, la empresa no le imponía la clase o número de pedidos que tenía que hacer ni la ruta para llevarlos a cabo, el pedido se realizaba siguiendo las instrucciones dadas por el cliente final — no por GLOVO_, entrando el repartidor en contacto directo con el cliente una vez aceptado el pedido. El actor decidía el cómo, el dónde y el cuándo de la prestación de servicios, tenía el dominio completo de su actividad y podía incluso desistir de un servicio previamente aceptado a mitad de ejecución sin sufrir por ello penalización alguna.

\section{De ahí que estime que}

ninguna de estas características son predicables de una relación laboral ordinaria, donde la persona trabajadora está sujeta a una jornada y horario, debe realizar las actividades encomendadas sin poder elegir cuales hace y cuáles no, debe seguir el método de trabajo impuesto por la empresa, y no puede negarse a realizar tareas y menos abandonarlas a mitad de ejecución sin exponerse a alguna suerte de sanción.

Además, la empresa no tiene poder disciplinario sobre la persona repartidora «más allá del desistimiento del propio contrato en el caso de que no se realizaran servicios (elemento consustancial a cualquier contrato bilateral), y de una pequeña "penalización” en su puntuación».

Destaca también que «el geolocalizador GPS no era un instrumento de control de la empresa, sino la forma de contabilizar el kilometraje para su posterior abono en la factura siguiente. No consta que se utilizara para controlar la ruta elegida por el actor en cada recado». Considera, en definitiva, que la ajenidad está ausente porque «las principales herramientas de trabajo (moto y teléfono móvil) son propiedad del trabajador, y la retribución que percibe depende directamente de la cantidad de recados que haga», asumiendo el riesgo y ventura de su actividad. En definitiva,

no consta el sometimiento del trabajador a una estructura organizativa interna de la empresa, que sólo decide las tarifas con que abonará los servicios, el lugar de prestación de los mismos, y la herramienta a través de la cual oferta los «recados» (APP) siguiendo un programa informático que busca minimizar la suma de costes.

En esta misma línea se pronuncia el Juzgado de lo Social núm. 17 de Madrid $^{21}$, que concluye que:

el repartidor tiene total libertad para elegir los días en los que quiere ofrecer su servicio a GLOVO y la franja horaria para entregar los productos de cada jornada laboral,

21 SJS núm. 17 Madrid, de 11 de enero de 2019, rec. núm. 418/2018. 
y para decidir sus jornadas de descanso. Asimismo, puede escoger si quiere prestar todos los servicios que le proponga la empresa (modalidad de asignación automática) aunque con la posibilidad de rechazar aquellos pedidos que no le interese realizar sin tener que justificar el motivo (pero debiendo comunicar el rechazo, para que el pedido sea asignado a otro repartidor) o bien aceptar uno a uno los pedidos que estén disponibles (modalidad de asignación manual). Incluso una vez iniciado el servicio, el repartidor puede elegir desistir del pedido para realizar otro o finalizarlo. También tiene total libertad de organización y decisión a la hora de seleccionar la ruta desde la posición inicial hasta la dirección de recogida y hasta la dirección de entrega sin tener establecida una trayectoria ni un punto concreto de localización para el inicio del servicio, aceptando el repartidor un modelo de facturación por distancia lineal o real óptima.

Asimismo, en la doctrina de suplicación, la STSJ Madrid, de 19 de septiembre de $2019^{22}$ se apoya en los siguientes argumentos. En primer lugar, parte de la libertad de elección de la franja horaria en la que desea trabajar, pudiendo fijar tanto la hora de inicio como la de finalización de su actividad, e incluso dentro de ese periodo, puede no activarse. En segundo lugar, tiene total libertad para aceptar los encargos o rechazarlos, sin que quede obligado a tener que realizar un mínimo de ellos. En tercer lugar, goza de libertad para elegir la ruta para llegar al destino fijado por el cliente, estableciéndose así una relación directa entre persona repartidora y cliente. En cuarto lugar, el rider realiza su actividad de forma personal sin tener personas trabajadoras a su cargo, y poniendo los recursos necesarios para realizar la actividad, esto es, una bicicleta o motocicleta y un teléfono móvil, asumiendo los gastos derivados de su uso. En quinto lugar, la retribución depende del número de servicios prestados, sin que venga fijada por unidad de tiempo. En sexto lugar, no existe un pacto de exclusividad, pudiendo compatibilizar sus tareas con otras de cualquier otra naturaleza. En séptimo lugar, está afiliada a la Seguridad Social y dada de alta en el RETA. Por último, no necesita justificar ninguna ausencia, siendo suficiente la mera comunicación de su no disponibilidad.

\section{Criterios de determinación en la calificación jurídica de los riders}

No cabe duda de que la calificación jurídica de estas personas repartidoras dependerá de la ponderación que obtengan, según los datos fácticos, en relación con las notas configuradoras de la relación laboral, destacando, como no, la nota de la dependencia y de la ajenidad.

De hecho, como indica la doctrina jurisprudencial, «la calificación de las relaciones jurídicas debe efectuarse siempre atendiendo a su verdadero fondo o

22 STSJ Madrid, de 19 de septiembre de 2019, rec. núm. 195/2019. 
contenido material, y no con base en el formal nomen iuris que las partes le hayan dado", ya que "la naturaleza jurídica de las instituciones viene determinada por la realidad de su contenido y (...) la misma debe prevalecer sobre el nomen iuris que errónea o interesadamente puedan darle las partes» ${ }^{23}$.

De ahí que, por consiguiente, no es determinante en absoluto el dato fático de que el rider esté incluido en el Régimen Especial de Trabajadores Autónomos, o que se realicen facturas que incluyen el IVA.

\section{1. Libertad y voluntariedad}

La voluntariedad en la prestación de estos servicios queda claramente evidenciada cuando es el propio rider quien de forma libre y voluntaria se registra en la App de Glovo para poder llevar a cabo los encargos. A ello debe unirse que el trabajo personal queda acreditado por los distintos contratos existentes, por facturas de diferente índole y la constancia de percepciones en modelos fiscales y contables.

\subsection{Retribución}

El hecho de que la empresa sea quien fija la forma de llevar acabo los pagos y la remuneración de los riders es muestra preclara de la subordinación económica de la persona trabajadora.

Concretamente, el precio por cada servicio lo fija la plataforma, que es quien lo comunica al cliente cuando realiza una solicitud. En su determinación influyen las variables tiempo y distancia, e incluye el IVA. Si no es posible calcular a priori las referidas variables, Glovo solo hace una estimación, también con IVA. En cualquiera de los dos supuestos, es al finalizar el transporte cuando la persona repartidora recibe de parte de la plataforma comunicación del precio final ${ }^{24}$.

Dicha cantidad a abonar por el cliente comprende el precio del producto, el del servicio de reparto y la comisión de Glovo por su intermediación, así como el coste de la actividad de la persona repartidora ${ }^{25}$. En cuanto a la forma de abono, se realiza directamente a la plataforma «en el momento de materializarse la entrega a través de la tarjeta de crédito facilitada por el usuario al registrarse en la aplicación» ${ }^{26}$. Cuando el servicio contratado incluya la adquisición de un producto en un establecimiento sin previo acuerdo comercial, será abonado por el rider en el momento de su retirada a través de la tarjeta de débito previamente facilitada por $\mathrm{Glovo}^{27}$.

23 STS de 19 de julio de 2018, rec. núm. 472/2017.

24 SJS núm. 1 Madrid, de 4 de abril de 2019, rec. núm. 496/2018.

25 SJS núm. 33 Madrid, de 11 de febrero de 2019, rec. núm. 1214/2018.

26 SJS núm. 24 Barcelona, de 29 de mayo de 2019, rec. núm. 144/2018.

27 SJS núm. 1 Madrid, de 4 de abril de 2019, rec. núm. 496/2018. 
De la cantidad abonada por parte del cliente, Glovo procede, por un lado, a pagar al establecimiento proveedor el producto consumido, previo descuento de las comisiones pactadas correspondientes por su intermediación. Y, por otro lado, paga al repartidor, previa emisión de facturas que la plataforma «elabora con los datos de los que dispone en la aplicación y atendiendo al precio por la actividad prestada» que también ella establece ${ }^{28}$. Las facturas se giran a cada rider con periodicidad quincenal y el pago se hace por transferencia bancaria ${ }^{29}$. Lo que se pacta es una cantidad por pedido, a la que se ańade otra por kilometraje y por tiempo de espera, con una deducción en concepto de pago por utilización de la plataforma.

Por tanto, como se observa, la persona repartidora percibe una retribución a destajo por tarea realizada (Álvarez Cuesta, 2017: 354), ya que se basa en el salario por unidad de obra, modalidad de retribución encajable sin obstáculo alguno en la relación laboral por cuenta ajena (Ginés i Fabrellas y Gálvez Durán, 2016: 18). La cantidad que se percibe por cada servicio se suele retribuir según los precios y tarifas fijados por la empresa que gestiona la plataforma, e incluso, en algunos casos, la empresa llega a garantizar unos servicios mínimos y, por tanto, una retribución mínima para los riders, satisfaciéndose así el cumplimiento de la ajenidad en los riesgos.

\subsection{Personalidad}

En cuanto a la nota de la naturaleza personal de la prestación de servicios, el encargo debe ser realizado por quien personalmente se ha comprometido a prestar el servicio, esto es, el concreto rider que está en contacto con la plataforma. Sin embargo, ello no es óbice para que, en ciertos casos, el prestador del servicio pueda delegar o subcontratar el servicio a otra persona, en cuyo caso, según el $\mathrm{TS}^{30}$, esta mera posibilidad de sustitución que no se ha materializado de un modo significativo en la práctica, no obsta a que se considere que sigue concurriendo el carácter personalísimo de la prestación de servicios. No obstante, en general, se incorporan unas cláusulas que prohíben la delegación de los servicios a terceros salvo excepciones, previa autorización o aceptación de la empresa. De hecho, los tribunales españoles han entendido en determinados supuestos que las posibilidades de sustitución de la persona trabajadora no desvirtúan la relación laboral convirtiendo ésta sin más y al amparo sólo de esa circunstancia en un arrendamiento de servicios ${ }^{31}$.

28 SJS núm. 33 Madrid, de 11 de febrero de 2019, rec. núm. 1214/2018.

29 SJS núm. 39 Madrid, de 3 de septiembre de 2018, rec. núm. 1353/2017.

30 STS de 23 de noviembre de 2009, rec. núm. 170/2009.

31 SSTS de 7 de octubre de 2009, rec. núm. 4169/2008; de 16 de noviembre de 2017, rec. núm. 2806/2015. También SSTSJ Navarra, de 30 de noviembre de 2017, rec. núm. 398/2017 y País Vasco, de 3 de octubre de 2017, rec. núm. 1680/2017. 


\subsection{Ajenidad}

En relación con la ajenidad, cabe señalar lo siguiente. Concretamente, en cuanto a la ajenidad en los medios de producción, ya se ha indicado que el grueso de la estructura se halla en la propia plataforma, constituyendo el teléfono móvil y la bicicleta, patinete eléctrico o motocicleta meros elementos accesorios. El auténtico medio de producción se halla en las plataformas digitales de estas empresas que tienen como fin poner en contacto a prestadores con clientes. Y, no cabe duda que la inversión en estas tecnologías es la parte más costosa económicamente de los medios de producción. Es decir, la inversión del rider en su equipo de trabajo - teléfono y medio de transporte- para llevar a cabo la tarea es insignificante, siendo la plataforma informática el eje sobre el que se sustenta este negocio. Según la doctrina (Luján Alcáraz, 2000: 4), esto se denomina criterio de desmerecimiento de los medios materiales respecto de la prestación de actividad. En definitiva, el hecho de que la persona trabajadora sea el titular de los medios de producción no desnaturaliza la relación laboral subyacente.

En relación con la ajenidad en los frutos, es evidente porque la empresa hace suyo el resultado de la actividad llevada a cabo por el rider, quien ha puesto a su disposición la utilidad patrimonial de su trabajo ${ }^{32}$.

Por lo que se refiere a la ajenidad en los riesgos, no cabe duda que los riesgos son asumidos por la plataforma, pues cuando un servicio no se presta adecuadamente y el cliente sufre un perjuicio, la responsabilidad recae en la empresa titular de la plataforma (González Ortega, 2017: 121), y no se opone a ello el hecho de que la persona repartidora deba responder ante el cliente final de los dańos o pérdidas que puedan sufrir los productos o mercancías durante el transporte, pues ello es compatible con el trabajo por cuenta ajena. Además, es la empresa propietaria de la plataforma la que debe asumir los posibles impagos del cliente, no recayendo esto sobre el prestador del servicio.

En cuanto a la ajenidad en el mercado también resulta claro que los clientes finales son clientes de la empresa titular de la plataforma, y no del rider, pues, es la plataforma la que negocia los términos del servicio, su precio y otras condiciones de ejecución. De ahí que sea la propia empresa propietaria de la plataforma la que realiza las campañas de captación de clientes y publicita la marca, además de ser ella quien fija el precio. En definitiva, el repartidor no puede prestar sus servicios fuera del marco de la plataforma digital. Es decir, el prestador de servicios no se relaciona con el mercado de un modo directo, sino que lo hace mediante la interposición de la plataforma digital, que es la que se relaciona con los clientes. En definitiva, la plataforma se configura como un intermediario imprescindible entre el cliente que efectúa el encargo y quien lo ejecute, sin que la

32 SJS núm. 33 Madrid, de 11 de febrero de 2019, rec. núm. 1214/2018. 
correspondiente actividad pueda ser factible al margen de la plataforma (Trillo Párraga, 2016).

\subsection{Dependencia o subordinación}

La subordinación o dependencia ha sufrido una relajación considerable, ya que el concepto tradicional de jerarquía y de organización empresarial se ha flexibilizado con los años.

De cualquier forma, como se analizará, en el campo de las plataformas digitales, la dependencia también concurre de forma evidente, pues el prestador de servicios queda totalmente sometido dentro del ámbito rector, organizativo y de dirección de la empresa gerente de la plataforma.

En primer lugar, un indicio de esta dependencia se puede extraer del dato de que existen unos procesos de selección de aquellas personas que van a prestar el servicio que oferta la plataforma digital (Ginés i Fabrellas y Gálvez Durán, 2016: 22). Ello constituye una manifestación clara de que la empresa no se limita a actuar como mera intermediadora, sino que está gestionando la prestación del servicio.

En segundo lugar, la plataforma es la encargada de dar formación a la persona repartidora. Asimismo, le da las instrucciones o indicaciones que debe tener en cuenta cuando lleve a cabo la actividad tanto sobre el uso del logotipo de la plataforma o sobre la forma de vestir. Además, aunque la propia plataforma titule estas indicaciones como meras sugerencias, ello es una muestra más de la dependencia (Moreno Gené, 2020).

En tercer lugar, como se ha indicado, la persona trabajadora queda totalmente controlada y vigilada tanto a través de la aplicación informática que el prestador ha tenido que descargarse en su teléfono móvil o tablet, como a través del GPS que registra su trayecto. Estas amplias posibilidades de control just in time mediante los datos obtenidos por la aplicación informática, entre los que se incluyen, las evaluaciones del servicio efectuadas por los clientes, se materializan en la valoración que realiza la empresa de cada persona repartidora.

En cuarto lugar, la empresa titular de la plataforma goza de amplias facultades de control en el sentido de que se premia a las personas repartidoras mejor valoradas y con mejores encargos, y, a sensu contrario, son «sancionadas» aquellas peor valoradas, que puede incluso, conllevar la baja unilateral del rider de la plataforma (Moreno Gené, 2020: 574). Glovo puede cambiar de categoría a los riders por el transcurso de tres meses sin aceptar ningún pedido, así como también puede penalizarlos dejando de asignarles pedidos si no están operativos en las franjas reservadas ${ }^{33}$. Incluso, puede llegar a bloquearles el acceso a la App

33 SJS núm. 39 Madrid, de 3 de septiembre de 2018, rec. núm. 1353/2017. 
cuando detecte inadecuadas conductas profesionales. En fin, una muestra más de la manifestación del poder de dirección empresarial en su vertiente de vigilancia y control efectivo del cumplimiento de la persona trabajadora y que necesariamente conlleva la facultad disciplinaria con aplicación de las correspondientes sanciones (Fernández Docampo, 2020: 174).

Además, aunque las personas repartidoras eligen, dos veces por semana, «los días y horas en que se comprometen a realizar su personal actividad, aun cuando posteriormente puedan desvincularse de dicho compromiso" ${ }^{34}$, no obstante, no acceden libremente a todas las franjas disponibles, ya que esa capacidad de decisión al final depende de la valoración obtenida. Para calcular dicha evaluación se tiene en cuenta la puntuación asignada por los consumidores finales, la satisfacción de los establecimientos, los pedidos realizados en horas de alta demanda y su índice de respuesta en los bloques horarios elegidos ${ }^{35}$.

Por último, tampoco se opone a la concurrencia de la dependencia, el hecho de que no se exija un deber de exclusividad en la prestación de servicios para una plataforma digital concreta, por cuanto en el contrato de trabajo la exclusividad sólo puede imponerse mediante pacto expreso de plena dedicación ex art. 21.1 ET. Es más, no es extraño que una persona sea al mismo tiempo rider de varias plataformas ${ }^{36}$.

\section{Régimen jurídico en el Derecho comparado}

\subsection{Italia}

En Italia existe una doble calificación, diferenciándose entre lavoratore subordinato y lavoratore autonomo.

El encuadramiento jurídico entre uno y otro se realiza en base a los datos fácticos, siendo irrelevante también la calificación que realicen las partes.

La noción de trabajo dependiente en Italia deriva del art. 2094 Código Civil Italiano, de 16 de marzo de 1942 (en adelante, CC italiano) que define a la persona que presta servicios de forma subordinada como una persona que se compromete «a colaborar en la empresa, prestando su trabajo (...) a cargo y bajo la dirección del empresario». Como se observa, el eje vertebrador es la sujeción personal del rider a las órdenes e instrucciones de la empresa. Se parte así de que el elemento que caracteriza el trabajo subordinado es la hetero-dirección que deriva en el poder de conformación de la prestación de servicios de la persona tra-

34 SSJS núm. 33 Madrid, de 11 de febrero de 2019, rec. núm. 1214/2018; núm. 1 Madrid, de 3 de abril de 2019, rec núm. 994/2018 y núm. 1 Madrid, de 4 de abril de 2019, rec. núm. 496/2018.

35 STSJ Asturias, de 25 de julio de 2019, rec. núm. 1143/2019.

36 SJS núm. 1 Madrid, de 4 de abril de 2019, rec. núm. 496/2018. 
bajadora a través de las instrucciones dadas por el superior jerárquico, así como en el poder de sancionar la conducta de incumplimiento (Varva y López Insua, 2019: 1010).

Por su parte, la figura de la persona trabajadora por cuenta propia se vertebra sobre el art. 2222 CC italiano, que define el contrato de servicios («contratto d'opera») como aquel por el que «un trabajador autónomo realiza trabajo o servicios a cambio de una remuneración, principalmente a través de su propio esfuerzo y en la ausencia de una relación de subordinación con respecto al principal».

En 2015 el Decreto Legislativo 81/2015, introduce el art. 2 por el que, y bajo la rúbrica Collaborazioni organizzate dal committente, extiende la protección "laboral» a quienes prestan un trabajo personal y continuado en el que la forma de ejecución está organizada por el comitente, incluso en lo que se refiere al lugar y al tiempo de trabajo. Posteriormente, en 2017, se modifica el art. 409 Código Procesal Civil, de 2 de febrero de 2006 (en adelante, C.p.c.) para referirse a la colaboración coordinada y continuada, esto es, aquella donde los colaboradores organizan su actividad de forma independiente, pero en base al citado acuerdo de coordinación.

Ello significa que la clave se halla en determinar si la prestación de servicios es organizada por el cliente, en cuyo caso la persona repartidora sería una persona trabajadora por cuenta ajena, o bien si se organiza por la propia persona trabajadora, aunque con cierta coordinación con el cliente, en cuyo caso se estaría ante una persona trabajadora por cuenta propia.

Siguiendo esta premisa, la Ley 128/2019, del trabajo a través de plataformas digitales, establece esta doble calificación, siendo la diferencia entre ambas figuras si la relación entre la persona trabajadora y la plataforma es o no permanente, de tal forma que cuando la relación tenga vocación de permanencia en el tiempo se estará ante una relación jurídico laboral, mientras que cuando se trate de una relación esporádica se tratará de una relación por cuenta propia. Desde el punto de vista de Seguridad Social significa que cuando la colaboración en la plataforma sea continua se deberá ofrecer la protección jurídico laboral y social propia del trabajo por cuenta ajena, incluyendo así un salario mínimo, derecho a disfrutar de vacaciones o cotización a la Seguridad Social, entre otros aspectos. Y, para aquellas personas repartidoras por cuenta propia, se prevén también una serie de derechos en aras a conseguir su protección y seguridad, aunque no de la misma entidad que las personas repartidoras asalariadas. Se prevén también políticas de no discriminación a los riders, de tal forma que la exclusión de la plataforma o la reducción del acceso a horas debido a la negativa de ejecutar un pedido están estrictamente prohibidas. Además, las plataformas deben contratar un seguro público obligatorio a sus riders por accidente o enfermedad laboral. 
Por su parte, de la doctrina judicial, cabe destacar la sentencia del Tribunal de Milán ${ }^{37}$ sobre una persona trabajadora que había realizado reparto de comidas preparadas con su propio automóvil a través de una plataforma digital. La persona trabajadora solicita que se califique como una relación laboral subordinada. El órgano judicial considera que no existen los elementos propios de subordinación, por lo que rechaza la demanda de la persona trabajadora. El órgano judicial parte de la libertad de la persona trabajadora para reservar las franjas horarias en las que desea prestar servicios; de la libertad para decidir si quiere prestar servicios o no, en qué días y durante cuantas horas; de la innecesaridad de garantizar un número mínimo de horas de trabajo; y de la libertad de la persona trabajadora de revocar o cambiar sus disponibilidades, sin repercusión alguna. En definitiva, el juez estima que la libertad con la que cuenta la persona repartidora para decidir si quiere realizar repartos y cuándo es un «elemento incompatible con el vínculo de subordinación».

Asimismo, la sentencia del Tribunal de Turín ${ }^{38}$, que analiza el caso de unas personas repartidoras que firmaron un acuerdo de colaboración con Foodora, en el que se pactó una remuneración predeterminada de 5,60 euros por hora de disponibilidad; que la entrega de los productos debía realizarse dentro de los 30 minutos a su aceptación, bajo pena de multa de 15 euros; y que en las fases de disponibilidad, las personas repartidoras debían estacionar en espera de pedidos en un lugar determinado, activando siempre, además, su geolocalización. El Tribunal de Turín vuelve a denegar su consideración de relación laboral partiendo de que las personas repartidoras no tenían obligación de realizar la prestación laboral y de que la empresa no tenía la obligación de recibirla.

De igual forma, la sentencia del Tribunal de Turín ${ }^{39}$ desestima también la calificación de la relación como laboral, al considerar que no existe subordinación. El órgano judicial parte de la interpretación de trabajo hetero-organizado, definido como un tertium genus, que comparte características tanto del trabajo por cuenta ajena como por cuenta propia. El tribunal estima que la hetero-organización aparece cuando existe una «integración funcional efectiva del trabajador en la organización de producción del comitente, de modo que la prestación laboral termina estando vinculada estructuralmente a esta y quede con algo que va más allá de la simple coordinación mencionada en el artículo 409 n.3 c.p.c., ya que aquí es el comitente quien determina las modalidades de la actividad laboral realizada por el colaborador».

Según un sector de la doctrina (Sánchez-Urán Azaña, 2019: 20) ello supone entender, pues, que hay que diferenciar, por un lado, entre el ejercicio del po-

\footnotetext{
37 St. Tribunal de Milán, de 10 de septiembre de 2018, st. núm. 1853.

38 St. Tribunal de Turín, de 7 de mayo de 2018, st. núm. 778.

39 St. Tribunal de Turín, de 11 de enero de 2019, st. núm. 26.
} 
der de gestión y disciplinario propio de la relación de subordinación según el art. 2094 Código Civil italiano; entre la heterogénea organización de la producción por el cliente que está comprendida en el ámbito de aplicación de la norma laboral; y, por otro lado, entre la colaboración coordinada según lo dispuesto en el art. 409.3 del c.p.c en la que es el colaborador quien, en coordinación con el cliente, organiza autónomamente su propia actividad laboral.

Sin embargo, su posición ha cambiado. Así, la sentencia del Tribunal de Bolonia ${ }^{40}$ declara el carácter discriminatorio de la actuación de la plataforma Deliveroo Italia S.R.L. en relación con las condiciones de acceso a la reserva de las jornadas de prestación de servicios a través de su plataforma digital, ya que estima que se utiliza un algoritmo de forma discriminatoria y que es desconocido por las personas repartidoras. De hecho, un sector (Rojo Torrecilla, 2021) ha señalado que «Deliveroo en ningún momento ha revelado como funciona el algoritmo Frank, lo que constituye un buen ejemplo de 'caja negra' para los riders y usuarios de su plataforma. Ha quedado demostrado que dicho algoritmo es ciego, y, por tanto, indiferente a las necesidades y motivaciones de los riders cuando se ausentan temporalmente de la plataforma, lo que en el caso concreto tiene repercusiones en el ejercicio de sus derechos fundamentales (igualdad y no discriminación, huelga, etc.)». La resolución judicial marca a su parecer un precedente interesante en Europa «que puede promover el inicio de acciones judiciales sobre la necesidad de la auditabilidad y explicabilidad de los algoritmos informáticos de las plataformas online, lo que a la postre significaría reclamar una mayor transparencia algorítmica». Asimismo, la sentencia condena a la plataforma a pagar a las personas repartidoras una indemnización por daños y perjuicios.

En la misma línea, la justicia italiana ha obligado el pasado 24 de febrero de 2021 a las plataformas de entrega a domicilio a que regularicen como asalariados a 60.000 repartidores, además de multarles por diversas irregularidades. El órgano judicial se basa en las precarias condiciones en las que trabajan estas personas repartidoras, que son obligadas a prestar sus servicios como personas autónomas, aunque deberían tener un contrato con condiciones detalladas de seguridad, formación, vestimenta y horarios adecuados, por parte de las empresas que las utilizan. El fiscal considera que estas personas repartidoras de comida «no pueden ser clasificados como autónomos", porque en realidad son empleados que llevan «toda la organización de las empresas para las que operan» (La Información, 2021).

\subsection{Francia}

Francia ha sido uno de los primeros países, como en otras ocasiones, en adaptar la normativa laboral a las nuevas realidades y necesidades sociales. Así,

40 St. Tribunal de Bolonia, de 31 de diciembre de 2020. 
en materia de plataformas digitales, se dicta la Ley n. ${ }^{\circ}$ 2008-766, de 22 de julio, de modernización de la economía, a través de la cual se crea el «auto-entrepreneur» y se implementan una serie de medidas para agilizar la puesta en marcha de su actividad profesional.

No obstante, es con la Ley n. $2016-1088$, de 8 de agosto, sobre el trabajo, la modernización del diálogo social y la garantía de los itinerarios profesionales y la Ley n. ${ }^{\circ}$ 2019-1428, de 24 de diciembre, de orientación de las movilidades, cuando se modifican diversos preceptos del Código de Trabajo, y se regulan las nuevas formas de prestación de servicios fijándose una serie de garantías de las personas repartidoras frente a las plataformas digitales.

Concretamente, la Ley n. ${ }^{o}$ 2016-1088, modifica el art. L.7342-1 Código del Trabajo que declara que «cuando la plataforma determina las características del servicio prestado o del bien vendido y fija su precio, tiene, respecto a los trabajadores afectados, una responsabilidad social que se ejerce en las condiciones previstas en el presente capítulo». Asimismo, el artículo L.7342-2 indica que

cuando el trabajador contrata un seguro que cubre los riesgos de accidentes de trabajo o se adhiere al seguro voluntario de accidentes de trabajo mencionado en el artículo L. 743-1 del Código de la Seguridad Social, la plataforma abona su cotización, hasta un límite máximo fijado por decreto. Este límite máximo no podrá ser superior a la contribución prevista en el mismo artículo L. 743-1. El párrafo primero de este artículo no se aplicará cuando la persona trabajadora se adhiera a un convenio colectivo suscrito por la plataforma y que contenga garantías al menos equivalentes al seguro voluntario de accidentes de trabajo mencionado en el párrafo primero, y la contribución a este contrato sea abonada por la plataforma.

Cuando el volumen de negocios realizado por la persona trabajadora en la plataforma sea inferior al umbral fijado por el Decreto, los arts. L. 7342-2 y 7342-3 no son aplicables.

Posteriormente, en diciembre de 2019 se publica la Ley n. ${ }^{\circ}$ 2019-1428, de 24 de diciembre, de orientación de las movilidades. En su título III, dedicado a «la revolución de las nuevas movilidades», se regula la incentivación de las innovaciones en esta materia, siendo su art. 44 (que modifica varios preceptos del Código de Trabajo), el dedicado a regular las nuevas formas de movilidad y reforzar la responsabilidad social de las plataformas. Se incluye el art. 20 en la Ley de Movilidad que desarrolla un estatuto de trabajo conocido como "Carta Social». En la citada Carta se definen los derechos y obligaciones de las plataformas y de las personas repartidoras. Entre ellos se establece que la relación entre las personas trabajadoras y la plataforma no es exclusiva, de tal forma que las personas trabajadoras puedan utilizar libremente la plataforma. Además, debe garantizarse que las personas trabajadoras puedan obtener un precio decente por sus servicios; así como garantizar unas condiciones de trabajo adecuadas; unas con- 
diciones de seguridad y salud suficientes; que exista un intercambio de información y diálogo entre la plataforma y las personas trabajadoras; y una protección social que garantice el riesgo de muerte, riesgos que afecten a la integridad física o vinculados a la maternidad, incapacidad laboral o invalidez, entre otras.

Esta Carta Social tiene como fin ofrecer una solución a la prestación de servicios a través de las plataformas digitales garantizando una mínima seguridad jurídica para empresas y personas trabajadoras. Dicha Carta, negociada previamente con las personas repartidoras, regula un conjunto de beneficios y elementos de la relación jurídica con las personas repartidoras, pudiéndose asimilar, en cierta forma, al «acuerdo de interés profesional» español de las personas trabajadoras autónomas económicamente independientes.

En el fondo, la razón de ser de esta Carta Social no es más que intentar que las plataformas asuman compromisos para mejor las condiciones de trabajo de las personas repartidoras, pero sin que ello suponga un riesgo jurídico para las plataformas, esto es, sin que ello suponga que las personas repartidoras se conviertan en personas trabajadoras por cuenta ajena. Es decir, como explica el preámbulo de la ley francesa, la Carta Social «define un nuevo marco de relación entre las plataformas digitales y los trabajadores independientes, aportando seguridad jurídica a unos y otros, sin por ello limitar la capacidad de las empresas de generar dinamismo y crecimiento en la economía y el empleo». Se garantiza el necesario respeto a estas plataformas, y hace un llamamiento a la política para que tome «el liderazgo de la adaptación a un mundo en transformación en el que la iniciativa privada debe ser una aliada en la búsqueda de soluciones, no un enemigo a batir» (Rojo Torrecilla, 2019).

De hecho, el Consejo constitucional francés ha tenido oportunidad de pronunciarse al respecto ${ }^{41}$ señalando que corresponde al legislador ejercer la competencia que le confiere la Constitución sin delegar en las autoridades judiciales o administrativas la tarea de elaborar nomas; que uno de los principios del Derecho del Trabajo es la determinación de su ámbito de aplicación, esto es, las características configuradoras de la relación laboral; y que si las personas que prestan servicios para las plataformas, en principio, lo realizan de forma independencia y amparados bajo una Carta Social, corresponde al juzgador reclasificar la relación cuando se evidencie la existencia de una relación de subordinación y por cuenta ajena. En definitiva, la existencia de una Carta Social no puede, por sí misma, caracterizar el vínculo de subordinación entre plataforma y persona repartidora, de tal forma, que se parte de la presunción de existencia de una relación no laboral entre la plataforma y las personas repartidoras, aunque ello no impide que, si concurren las notas configuradoras, sea calificada de laboral.

41 Décision n $^{\circ}$ 2019-794 DC du 20 décembre 2019. Disponible en https: //www.conseil-constitutionnel.fr/decision/2019/2019794DC.htm 
En el ámbito judicial, la Cour D’Appel de París ${ }^{42}$ califica la relación de las personas prestadoras del servicio con UBER como laboral. Considera que la persona conductora no es libre de elegir a sus clientes, siendo la plataforma quien centraliza y gestiona las peticiones asignándolas mediante algoritmos. Y, en cuanto al precio, considera que las tarifas vienen fijadas contractualmente mediante dichos algoritmos. Además, considera que existe un poder de dirección porque la plataforma da instrucciones a las personas conductoras, y ejerce un poder de control sobre ellas.

Asimismo, la Cour de Cassation ${ }^{43}$ considera que también existe una relación laboral entre las personas repartidoras y las plataformas digitales. Para ello, parte del art. L 822 1-6 II (reforma de 2016) Código de Trabajo, que no establece una presunción del trabajo no asalariado, y que, además, con independencia del nomen que las partes le den al contrato entre ambas, la persona trabajadora es aquella que realiza un trabajo en una relación de subordinación, de tal forma que la existencia de una relación laboral no depende de la voluntad expresada por las partes o del nombre, sino de la realidad fáctica, de los hechos. Como indica en una antigua sentencia ${ }^{44}$, una relación de subordinación viene caracterizada por la realización de un trabajo bajo la autoridad de una empresa que tiene la facultad de dictar órdenes e instrucciones sobre la actividad a desarrollar, así como supervisar el cumplimiento y castigar las infracciones.

\section{A modo de reflexión}

Esta nueva forma de organización y de prestación de servicios conlleva la necesidad de replantear las estructuras tradicionales sobre las que se sustenta la relación laboral por cuenta ajena, siendo necesaria una adaptación a las nuevas realidades sociales, a la nueva realidad digital y a la revolución digital propia de la industria 5.0.

Se requiere una reinterpretación de las notas configuradoras de la relación laboral, especialmente, la dependencia y la ajenidad, características que deben ser adaptadas a la nueva realidad digital, a las actuales formas de prestación de servicios.

Así lo señala el Dictamen del Comité Europeo de las Regiones-Trabajo en plataformas digitales: retos normativos en las esferas local y regional que «reconoce la complejidad de las relaciones contractuales en las plataformas digitales, si bien señala que los modelos de empleo de la economía tradicional también se

\footnotetext{
42 St. de 10 de enero de 2019, Asunto UVER.

43 St. de 28 de noviembre de 2018, Asunto Take Eat Easy.

44 St. de 13 de noviembre de 1996.
} 
encuentran muy diversificados, sin que dejen por ello de estar sujetos a normas básicas comunes, que se aplican del mismo modo a todos los operadores. Por consiguiente, el CDR pide que se transpongan a la economía de las plataformas y a sus trabajadores las disposiciones laborales y sociales fundamentales, subrayando la necesidad de afrontar a nivel europeo el impacto social del mercado único digital. Una regulación adecuada a nivel nacional $-\mathrm{y}$, cuando sea necesario, a nivel europeo, habida cuenta de la dimensión transnacional de la economía digital — que afronte los retos normativos en las plataformas digitales creará unas condiciones de competencia equitativas entre la economía tradicional y la economía de las plataformas digitales y combatirá el dumping social. Esta regulación debe considerar asimismo prohibir cláusulas de exclusividad que impidan a los trabajadores cooperar con otras plataformas» ${ }^{45}$.

Se requiere, pues, adaptar la legislación laboral para dar respuesta a este colectivo de personas trabajadoras, debiéndose llevar a cabo una modificación legislativa que permita proteger a esta nueva figura. El debate doctrinal se proyecta desde su consideración como personas trabajadoras por cuenta ajena hasta llegar al extremo de su calificación como personas trabajadoras por cuenta propia, y la de personas trabajadoras autónomas económicamente dependientes.

No cabe duda de la posibilidad de realizar una interpretación adaptativa de los indicios de laboralidad que acoja nuevas concepciones de la dependencia y la ajenidad basadas en la digitalización, pero también es posible su exclusión por encontrar demasiadas debilidades.

La presunción de laboralidad que fija el RDL 9/2021 establece unos requisitos más exigentes que los del art. 8.1 ET. Ello significa que, según el art. 8.1 ET, y según la doctrina jurisprudencial, implica que la inversión de la carga de la prueba se producirá siempre que exista un contrato de prestación de servicios retribuido, en cuyo caso, la persona trabajadora únicamente deberá demostrar que presta servicios a cambio de una retribución. Y, una vez acreditados dichos extremos, el órgano judicial declarará la laboralidad, salvo que la empresa pueda demostrar que la prestación de servicios se presta con independencia y por cuenta propia. Pero, según, el RDL 9/2021, se exigen más requisitos, tales como, que las actividades sean de reparto; que la empresa ejerza facultades de dirección a través de una plataforma digital; y que use un algoritmo para gestionar el servicio o determinar las condiciones de trabajo (Todolí Signes, 2021).

Ello es una muestra clara de las dificultades para llegar a un acuerdo en el diálogo social. Esta presunción, por la que abogaba la parte patronal, reduce la

45 Comité Europeo de las Regiones (2020) Dictamen del Comité Europeo de las Regiones-Trabajo en plataformas digitales: retos normativos en las esferas local y regional (2020/C 79/07). Disponible en https: //eur-lex.europa.eu/legal-content/ES/TXT/PDF/?uri=CELEX: 52019IR2655\&from=ES (consultado el 26-5-2021) 
efectividad de la norma al limitar sus efectos a los de carácter procesal. Pero, al mismo tiempo, dicha formulación complace los intereses de los sindicatos, que implica que todos aquellos que cumplan dichos requisitos serán incluidos en el ámbito de aplicación del ET.

De esta forma, podría incluso alegarse que la disposición del citado RDL se puede interpretar desde dos puntos de vista. Por un lado, entender que se está ante una presunción iruis tantum, y, por otro lado, considerar que se está ante una presunción iuris et de iure, de tal forma que, si se cumplen los requisitos de la citada disposición, se convierte en una relación laboral. No obstante, un sector doctrinal (Todolí Signes, 2021), al que me uno, estima que debe entenderse que lo correcto es la primera interpretación, pues, aunque se cumplieran todos los requisitos de la citada disposición, el órgano judicial deberá declarar la no laboralidad si la empresa demuestra que no concurren los requisitos de laboralidad.

Sin embargo, no creo que la intervención legislativa realizada dé respuesta a toda la problemática que surge en relación con estos colectivos, pues la presunción de laboralidad exige la concurrencia de diversos requisitos nada claros y que darán lugar a conflictos interpretativos. Considero que debería haberse aclararse más esta actuación legislativa para evitar futuros litigios.

Como hemos señalado, en algunos países de nuestro entorno y con los que compartimos criterios de base de la configuración del Derecho común y, por extensión, del Derecho laboral, se ha optado por una doble conceptuación que permite acoger a todas las posibilidades de prestación de servicios por parte de las personas trabajadoras. Se parte, básicamente, de encuadrarlas tanto en el régimen de personas trabajadoras por cuenta ajena, así como en el de personas trabajadoras por cuenta propia, siendo el elemento diferenciador su carácter de permanencia (Italia) o el del volumen de servicios prestados (Francia). No consideramos que crear una figura tertium genus sea la solución más adecuada para poder ofrecer una respuesta a esta controversia. Se requiere, más bien, depurar esa zona gris calificándola como relación laboral por cuenta ajena o bien por cuenta propia en base al criterio de la ocasionalidad/durabilidad de la prestación de servicios.

Debería considerarse, pues, el establecimiento de un modelo flexible que permita analizar en cada caso si concurre o no el elemento de laboralidad para considerar que se está ante una persona repartidora por cuenta ajena, siendo, dicho elemento, el carácter continuo y duradero de la prestación de servicios. En caso contrario, esto es, cuando se trate de una prestación ocasional debería ser calificado como una persona trabajadora por cuenta propia.

Por otro lado, no debe olvidarse la responsabilidad social y ética que recae sobre la plataforma, esto es, a la concienciación y cultura de la plataforma. Es decir, se trata de que las plataformas sean conscientes y no traten de eludir los derechos y obligaciones, recurriendo a prácticas antisociales. 


\section{Bibliografía}

Álvarez Cuesta, Henar (2017) «Los retos de la economía colaborativa en la prevención de riesgos laborales». En Escudero Prieto, Azucena (Dir.) Los nuevos perfiles del Estado social. La promoción del empleo de los trabajadores jóvenes y maduros. Madrid: Reus.

Camara Botía, Alberto (2019) «La prestación de servicios en plataformas digitales: trabajo dependiente o autónomo», Nueva Revista Española de Derecho del Trabajo, núm. 222.

Cavas Martínez, Faustino (2019) «Breves apuntes para una regulación multinivel del trabajo en plataformas digitales», Revista de Derecho Social, núm. 87.

Comisión Europea (2016) Una Agenda Europea para la economía colaborativa, Bruselas, 2 de junio de 2016 [COM (2016) 356 final]. Disponible en https: //eur-lex.europa.eu/ legal-content/ES/ALL/?uri=CELEX: 52016DC0356 (consultado el 26-5-2021)

Comité Europeo de las Regiones (2020) Dictamen del Comité Europeo de las Regiones Trabajo en plataformas digitales: retos normativos en las esferas local y regional (2020/C 79/07). Disponible en https: //eur-lex.europa.eu/legal-content/ES/TXT/ PDF/?uri=CELEX: 52019IR2655\&from=ES (consultado el 26-5-2021

Fernández Docampo, M.a Belén (2020) «Análisis casuístico de la prestación de servicios de los riders de glovo a través del contenido fáctico de las resoluciones judiciales», $T e$ mas Laborales, núm. 151.

Galiana Moreno, José María y Selma Penalva, Alejandra (2009) «El trabajo autónomo dependiente dos años después de la aprobación del Estatuto del Trabajador Autónomo. Aportaciones prácticas del RD 197/2009 que desarrolla la Ley 20/2007», Revista del Ministerio de Trabajo e Inmigración, núm. 83.

Ginés i Fabrellas, Ana y Gálvez Durán, Sergi (2016) «Sharing economy vs. Uber economy y las fronteras del Derecho del Trabajo. La (des)protección de los trabajadores en el nuevo entorno digital», Indret: Revista para el análisis del Derecho del Trabajo, núm. 1.

GonzÁlez Ortega, Santiago (2017) «Trabajo asalariado y trabajo autónomo en las actividades profesionales a través de las plataformas informáticas», Temas Laborales, núm. 138.

Jover Ramírez, Carolina, (2018) «El fenómeno de la gig economy y su incidencia en el derecho del trabajo: aplicabilidad del ordenamiento jurídico laboral británico y español», Nueva Revista Española de Derecho del Trabajo, núm. 209.

La Información (2021) «Italia también obliga a regularizar a casi 60.000 'riders' de cuatro plataformas», La Información. Disponible en https: //www.lainformacion.com/economia-negocios-y-finanzas/italia-obliga-regularizar-riders-glovo-just-eat-deliveroo-ubereats/2830476/ (consultado el 26-5-2021)

Luján Alcáraz, José (2000) «Las notas de laboralidad. Una aproximación en clave jurisprudencial», Aranzadi Social, núm. 16.

Montoya Melgar, Alfredo (2005) «Trabajo dependiente y trabajo autónomo ante el Derecho del Trabajo», Temas Laborales, núm. 81.

Moreno Gené, Josep (2020) «El carácter laboral de la prestación de servicios a través de plataformas digitales: el caso de Glovo. Comentario a la sentencia del Tribunal Superior de Justicia de Cataluña de 21 de febrero de 2020", Revista General de Derecho del Trabajo y de la Seguridad Social, núm. 57.

Oliva León, Ricardo (2020) «¿Es discriminatorio el algoritmo de Deliveroo que rankea a sus riders?», Algoritmo legal (blog). Disponible en https: //www.algoritmolegal.com/ tecnologias-disruptivas/es-discriminatorio-el-algoritmo-de-deliveroo-que-rankea-asus-riders/ (consultado el 26-5-2021) 
Prieto Padín, Patricia (2020) «La calificación jurídica de TRADE en la prestación de servicios a través de las plataformas digitales delivery: una solución contractual y judicial en entredicho", Revista General de Derecho del Trabajo y de la Seguridad Social, núm. 56.

Rojo Torrecilla, Eduardo (2019) «La regulación contractual de los trabajadores de plataformas en Francia. Lo que se quiere contar, y lo que se debe explicar. A propósito de la Ley de 24 de diciembre de 2019 de orientación de las movilidades», El nuevo y cambiante mundo del trabajo. Una mirada abierta y crítica a las nuevas realidades laborales [blog]. Disponible en http: //www.eduardorojotorrecilla.es/2019/12/la-regulacioncontractual-de-los.html (consultado el 26-5-2021)

Sáenz de Buruaga Azcargorta, María (2019) «Implicaciones de la gig-economy en las relaciones laborales: el caso de la plataforma Uber», Estudios de Deusto, vol. 67, núm. 1.

Todolí Signes, Adrián (2021) «Nueva Ley Rider. Texto y un pequeño comentario a la norma», Argumentos en Derecho Laboral [blog]. Disponible en https: //adriantodoli. com/2021/05/12/nueva-ley-rider-texto-y-un-pequeno-comentario-a-la-norma/ (consultado el 26-5-2021)

Trillo PÁrraga, Francisco (2016) «Economía digitalizada y relaciones de trabajo», Revista de Derecho Social, núm. 76.

Varva, Simone y López Insua, Belén del Mar (2019) «Plataformas digitales: una perspectiva comparada en los ordenamientos italiano y español», Derecho de las Relaciones Laborales, núm. 10 . 